\title{
THE ROLE OF JOB DEMANDS AND JOB RESOURCES MODEL ON JOB RELATED STRAIN AND SAFETY BEHAVIORS: A RESEARCH ON BLUE-COLLAR WORKERS
}

\author{
DOI: 10.17261/Pressacademia.2019.1060 \\ PAP- V.9-2019(7)-p.29-35
}

Selahattin Kanten ${ }^{1}$, Pelin Kanten ${ }^{2}$, Merve G.Durmaz ${ }^{3}$, Esra Burcu Kaya ${ }^{4}$, Yigit Akkoyun ${ }^{5}$

${ }^{1}$ Canakkale Onsekiz Mart University, Faculty of Biga Applied Science, Canakkale, Turkey

skanten@comu.edu.tr, 0000-0001-7414-8495

${ }^{2}$ Canakkale Onsekiz Mart University, Faculty of Political Sciences, Canakkale, Turkey

pelinkanten@comu.edu.tr, ORCID: 0000-0002-6487-0203

${ }^{3}$ Canakkale Onsekiz Mart University, Faculty of Political Sciences, Canakkale, Turkey

mervegozdedurmaz@gmail.com, ORCID: 0000-0003-1000-8316

${ }^{4}$ Canakkale Onsekiz Mart University, Faculty of Biga Applied Science, Canakkale, Turkey

burcukaya017@gmail.com, ORCID: 0000-0002-0300-8636

${ }^{5}$ Canakkale Onsekiz Mart University, Faculty of Political Sciences, Canakkale, Turkey

yigitakkoyun17@gmail.com, ORCID: 0000-0001-9878-5130

\section{To cite this document}

Kanten, S., Kanten, P., Durmaz, M.G., Kaya, E.B., Akkoyun, Y., (2019). The role of job demands and job resources model on job related strain and safety behaviors: a research on blue-collar workers. PressAcademia Procedia (PAP), V.9, p.29-35

Permemant link to this document: http://doi.org/10.17261/Pressacademia.2019.1060

Copyright: Published by PressAcademia and limited licenced re-use rights only.

\begin{abstract}
Purpose- This study aims to investigate the effects of job demands and job resources model on blue collar employees' job related strain and safety behavior levels.

Methodology- For the purpose of the research, the data which were collected from 235 blue collar workers from one of the transportation company by the survey method were analyzed by using partial least squares-structural equation modeling method. While conducting analysis, Smart PLS program was used by applying bootstrapping technique (5000 resample) to determine the significance levels of the proposed hypotheses and also Anderson and Gerbing (1988) two-step approach has been used.

Findings- Research results indicate that some of the dimensions of job demands labelled as work overload, role ambiguity and job insecurity have a positive and significant effect on job related strain. However, job insecurity has a negative and significant effect on employees' safety behaviors. In addition, research results show that one of the component of job resources which is addressed as organizational support has a positive and significant effect on employees' safety behaviors.

Conclusion- The study reveals that job demands and job resources are the significant determinants of the job related strain and safety behaviors. Therefore, it can be concluded that in order to remove unsafe behaviors and decreasing job related strain, organizations need to maintain favourable working conditions which considers work life balance and employees' well-being.
\end{abstract}

Keywords: Job demands, job resources, job related strain, safety behavior, blue collar JEL Codes: M10, M20, M54

\section{INTRODUCTION}

Due to the human resources are considered as a vital assets of a sustainable and success organizations, it is required to prioritise providing healthy working conditions which lead to motivation of employees in the long term (Adil and Baig, 2018: 119). In other words, organizations need to maintain favourable working environment in order to attract and retain qualified individuals and also ensure employee well-being. However, it is suggested that employee's wellbeing or ill-being can be explained one of the leading framework called as job demands and job resources model. According to this comprehensive model while the determinants of unfavourable psychological conditions accounts for job demands; other motivational outcomes like engagement, commitment and positive behaviors account for job resources (Fernet et al., 2012: 213-214). Job demands include work overload, role ambiguity, time pressure and etc that lead to negative consequences such as burnout, depression and strain; job resources composed of organizational support, autonomy, feedback and development which may have positive effect on well-being, motivation and performance (Wolter et al., 2019: 45). In addition, due to job demands required sustained extra physical and psychological effort, it is expected to occur physiological and psychological costs which lead to serious health problems and workplace outcomes such as unsafe behaviors, accidents, injuries, and fatalities (Nahrgang et al., 2010: 1). Besides, it is asserted that job resources which provides 
instrintic and extrintic motivation may increase employees willingness to make an effort for developing themselves and achieving organizational goals and have a tendency to exhibit favourable attitudes (Hansez and Chmiel, 2010: 268). Therefore, it is possible to express that job demands and job resources are considered as one of the significant predictors of both psychological health problems and workplace behaviors. In this context, this study aims to examine both individual and organizational consequences of job demands and job resources model on blue collar workers as these employees encountered more job demands and its detrimental effects. As scope of the individual consequences job related strain and from the organizational perspective safety behaviors are investigated. However, there is no research in the existing literature yet examining the relationships among job demand and job resources model, job related strain and safety behavior together, so it aims to explain some consequences of this model and attempts to add contribution to the literature.

\section{THEORETICAL FRAMEWORK AND HYPOTHESES DEVELOPMENT}

In modern age, due to work takes an important part of life, individuals need to posseses some specific jobs or occupations in order to ensure personel and unique value in the society. However, every job or occupation create ambivalent feelings which include demands and resources simultaneously (Strydom, 2005: 2). Therefore, job demands and job resources model based on the main assumption asserted that jobs contain some specific risk factors which is associated with job related strain. Accordingly, these factors classified under two categories such as job demands and job resources (Demerouti and Bakker, 2011: 1). Job demands refer to the "physical, social or organizational aspects of the job which requires psyhical and cognitive effort and result in serious health problems. Besides, job resources can be defined as "physical, social or organizational aspects of the job that are facilitate achieving work goals and personel development (Wingerden et al., 2016: 686; Chavarria, 2016: 25). In other words, while job demands called as "bad things" at work which lead to depletion of energy such as work overload, role conflict, role ambiguity and job insecurity. Job resources characterized as "good things" that represent organizational support, job control, feedback and autonomy (Schaufeli, 2017: 121). Job demands and job resources which are based on the job characteristics theory explains that employees may encountered two different consequences as health impairment process and movational process in working organizations. While health impairment process consists of unfavourable outcomes such as burnout, emotional exhaustion, health problems and job related strain; the motivational process refers to the job resources which produce positive conditions like engagement and commitment (Wolter et al., 2019: 46). Job related strain shows "the balance between work overload, time pressure, conlict demands and freedom to decide and control how to perform tasks (Turcotte and Schellenberg, 2005: 13). However, job strain defined as a psychological health problem which occurs combination of high job demands and low job resources (Lopes et al., 2009: 2). Accordingly, it can be inferred that job demands and job resources are significant predictors of job related strain. Recent studies Demerouti et al., (2001); Bakker and Demerouti (2007); Lopes et al (2009); Brough et al. (2013); Schaueli (2017); Wolter et al., (2019) asserted that health problems such as job related strain triggered based on the high job demands and low job resources. In this context, it is possible to express that high job demands (work overload, role ambiguity, job insecurity) and job resources (organizational support) may have a significant effect on job related strain levels of employees, so the following hypotheses are proposed:

$\mathrm{H}_{1}$ : Work overload influences employees' job related strain levels positively.

$\mathrm{H}_{2}$ : Role ambiguity influences employees' job related strain levels positively.

$\mathrm{H}_{3}$ : Job insecurity influences employees' job related strain levels positively.

$\mathrm{H}_{4}$ : Organizational support influences employees' job related strain levels negatively.

Job demands and job resources model emphasize that incase of the job demands lead to the depletion of mental and psyhical efforts, it is expected that individuals ignore the activities which is related to safety due to the high work and time pressure. On the contrary, while employees possess high job resources, they have power to make an effort maintaining safety conditions based on the favourable working area (Bronkhorst et al., 2015: 64). In other words, it is suggested that if employees perceive supportive organization conditions, they may inclined to safety partipation. Therefore, it can be inferred that job demands and job resources are considered as the crucial antecedents of safety behaviors (Hansez and Chmiel, 2010: 268). Safety behavior refers to the how employees comply with the organizations safety procedures while performing their job (Khan et al., 2014: 258). However, safety behavior is defined as set of actions which aims to promote the health and safety of workers, customers, public and the environment. These behaviors include making individuals aware towards to the dangerous conditions, taking safety precautions, using safety equipments, reporting incidents and etc. (DeArmond and Chen, 2009: 977). Due to the safety behavior have a significant effect on work related outcomes and quality of life of employees, organizations need to understand its antecedents and how can be developed an insight for developing these behaviors (Ju et al., 2016: 114). As scope of the antecedents; it is seen that some individual components such as personality traits, abilities, gender, age, educational status and organizational factors like organizational culture, organizational climate and job characteristics considered determinants of safety behavior (Kanten, 2018: 319). For example, Turner et al. (2010); Hansez and Chmiel (2010); Nahrgang et al., (2010); Li et al. (2013); Fernández-Mu niz et al. (2012); Bronkhorst (2015) studies asserted that job demands (work overload, role ambiguity, role conflict, job insecurity) and job resources (job control, autonomy, feedback, organizational support) related with the safety outcomes such as (safety behaviors, accidents and injuries). Accordingly, the following hypotheses are proposed:

$\mathrm{H}_{5}$ : Work overload influences employees' safety behavior levels negatively.

$\mathrm{H}_{6}$ : Role ambiguity influences employees' safety behavior levels negatively.

$\mathrm{H}_{7}$ : Job insecurity influences employees' safety behavior levels negatively.

$\mathrm{H}_{8}$ : Organizational support influences employees' safety behavior levels positively. 
Figure 1: Research Model

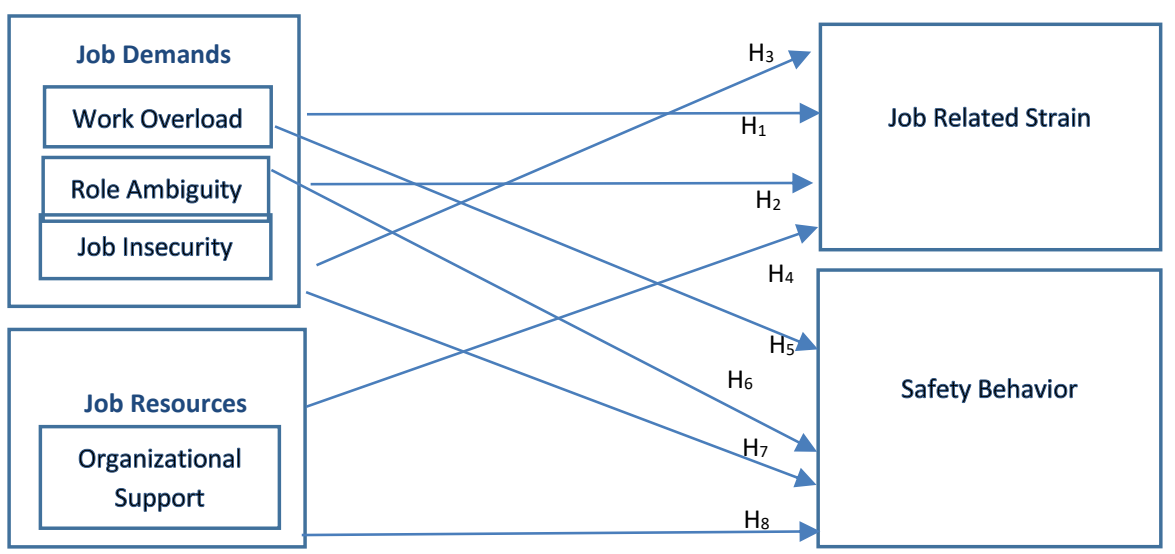

\section{RESEARCH METHODOLOGY}

\subsection{Sample and Procedures}

The sample of the research was constituted one of the major transportation company's employees which is located in Çanakkale province. Participants of the study has been composed of 235 blue collar workers in this company's various branches determined by a convenient sampling method. Out of 280 questionnaires that have been sent out, 256 have been returned, representing a response rate of $91 \%$. After the elimination of the cases that have incomplete data and outliers, 235 questionnaires ( $84 \%$ ) have been accepted as valid and included in the evaluations. However, questionnaire survey method is used for data collection in this study. The questionnaire form contains six different measures related to research variables. Majority of the respondents $81 \%$ were male and $19 \%$ were female; $47 \%$ of blue collar workers were between 30 and 39 years, $32 \%$ of them were older than 40 years and $21 \%$ of were between ages $20-29 ; 50 \%$ of the total respondents had a high school degree, $27 \%$ of them had a vocational school degree, whereas $6 \%$ had a bachelor's degree and $17 \%$ had a primary school degree. From the working position perspective, $25 \%$ of them working as a ticket officer, $23 \%$ of these employees working as a groundkeeper, $\% 18$ of them were working as a captain, $17 \%$ of them working as a security personnel and $17 \%$ of the blue collar employees were working as a cleaner. However, $18 \%$ of the employees reported that they had exposed to occupational hazards and dangers, while $7 \%$ reported that they had experienced occupational accidents. In addition to these, $72 \%$ of the employees reported that they had an outpatient treatment, $22 \%$ of them absence from work due to the injuries and $6 \%$ of them had a severe injuries.

\subsection{Measures}

The measures used in the questionnaire forms have been adapted from the previous studies in the literature. Job demands, job resources, job related strain and safety behavior scales were taken from the literature. Some of the measures have been adapted to Turkish by the lecturers and a pilot study has been conducted for the validity of these measures. As a result of the pilot study, some corrections were made in the questionnaire forms. A Likert-type metric, that is, expressions with five intervals has been used for answers to the statements of survey. Anchored such; "1- strongly disagree, 2- disagree, 3- agree or not agree, 4- agree, 5-strongly agree". Moreover, 8 demographic questions were included in the questionnaire form. Firstly, all scales were subjected to the exploratory factor analyses to check the dimensions, and then confirmatory factor analyses were applied to all scales.

- Job Demands and Job Resources Scale: Employees job demand and job resources perception were measured with 27 items which was developed by Strydom (2005). According to this model as scope of the job demands (work overload, job ambiguity and job insecurity); from the job resources perspective (organizational support) dimension were taken. As a result of the job demands and job resources scale variables, 8 items were removed from the analysis due to the factor loading under 0.50 and four factor solutions (work overload, role ambiguity, organizational support and job insecurity) were obtained in accordance with the theoretical structure. Some examples of the items asked to the employees are as follows: "We usually work under time pressure"; "We are generally appreciated by our supervisor"; "We are concerned about our job in future"

- Job Related Strain Scale: Employees job related strain levels were measured with 15 items which was adapted to Turkish by Aslan et al. (1998). As a result of the exploratory factor analyses, 9 items were removed from the analysis due to the factor loading under 0.50 and one factor solution were obtained in accordance with the theoretical structure. Some examples of the items asked to the employees are as follows: "I usually feel myself more nervous before"; "I usually go work late"

- Safety Behavior Scale: Employees safety behavior levels were measured with 21 questions which were taken from Seo (2005) and Fernández-Mu'niz et al. (2012) studies. As a result of the exploratory factor analyses, 8 items were removed from the analysis due to the factor loading under 0.50 and three factor solutions (safety compliance, safety participation, using protective equipment) were obtained in accordance with the theoretical structure. Some examples of the items asked to the employees are as follows: "We always comply with the safety rules and procedures although they make it harder to do their job"; "We wear personal protection equipment despite the discomfort". 


\subsection{Data Analysis}

SPSS for Windows 22 and SmartPLS v3 were used inorder to analyze obtained data. SPSS 22 were used for the descriptive statistics and reliability analysis. Smart PLS v3 were used for testing the hypotheses by employing partial least squares-structural equation (PLS) modeling method. PLS considered as an appropriate method due to its flexibility in distributional assumptions and its strength

handling complex predictive models with few items (Roy et al., 2016: 245). Consistent with the literature, according to PLS model, data were analyzed and interpreted based on Anderson and Gerbing (1988) two-step approach. Therefore, first the validity and reliability of the measurement model was tested, then conducting by structural model hypotheses were tested.

\section{RESEARCH FINDINGS}

\subsection{Measurement Model}

As scope of the measurement model, convergent validity and discriminant validity were tested. Within the convergent validity, factor loadings, composite reliability (CR), and average variance extracted values were computed. Table 1 shows that factor loadings exceeded the recommended value of 0.6 ; composite reliability values greater than the recommended value of 0.7 and also average variance extracted is exceeded the recommended value of 0.5 (Hair et al., 2006).

Table 1: Summary Table of Validity and Reliability

\begin{tabular}{|l|l|c|c|c|c|}
\hline \multicolumn{2}{|c|}{ Variables } & \multicolumn{1}{c|}{$\begin{array}{c}\text { Factor } \\
\text { Loadings }\end{array}$} & $\begin{array}{c}\text { Cronbach's } \\
\text { Alpha }\end{array}$ & $\begin{array}{c}\text { Composite } \\
\text { Reliability }\end{array}$ & $\begin{array}{c}\text { Average Variance } \\
\text { Extracted (AVE) }\end{array}$ \\
\hline \multirow{3}{*}{ Job Demands } & Work Overload & $0.546-0.861$ & 0.733 & 0.827 & 0.552 \\
\cline { 2 - 6 } & Role Ambiguity & $0.749-0.835$ & 0.882 & 0.909 & 0.626 \\
\cline { 2 - 6 } & Job Insecurity & $0.664-0.813$ & 0.776 & 0.849 & 0.530 \\
\hline Job Resources & Organizational Support & $0.745-0.852$ & 0.892 & 0.918 & 0.650 \\
\hline Job Related Strain & $0.670-0.796$ & 0.813 & 0.865 & 0.518 \\
\hline Safety Behavior & $0.657-0.758$ & 0.884 & 0.903 & 0.509 \\
\hline
\end{tabular}

After validity and reliability analyses, discriminant validity analysis were conducted. Discriminant validity provided when the square root of the AVE (diagonal values) of each construct is larger than its corresponding correlation coefficients (Fornell \& Larcker, 1981). Table 2 shows that each indicator's loadings on its own construct are higher than all cross loadings with other constructs. Therefore, it is possible to express that discriminant validity and convergent validity criteras were provided.

Table 2: Discriminant Validity

\begin{tabular}{|l|c|c|l|l|l|l|}
\hline & Work Overload & Safety Behavior & $\begin{array}{l}\text { Role } \\
\text { Ambiguity }\end{array}$ & $\begin{array}{l}\text { Organizational } \\
\text { Support }\end{array}$ & $\begin{array}{l}\text { Job } \\
\text { Insecurity }\end{array}$ & $\begin{array}{l}\text { Job Related } \\
\text { Strain }\end{array}$ \\
\hline Work Overload & $\mathbf{0 . 7 4 3}$ & & & & & \\
\hline Safety Behavior & -0.181 & $\mathbf{0 . 7 1 3}$ & & & & \\
\hline Role Ambiguity & 0.476 & -0.233 & $\mathbf{0 . 7 9 1}$ & & & \\
\hline $\begin{array}{l}\text { Organizational } \\
\text { Support }\end{array}$ & -0.046 & 0.317 & -0.344 & $\mathbf{0 . 8 0 6}$ & & \\
\hline Job Insecurity & 0.268 & 0.350 & 0.496 & -0.500 & $\mathbf{0 . 7 2 8}$ & \\
\hline $\begin{array}{l}\text { Job Related } \\
\text { Strain }\end{array}$ & 0.656 & -0.196 & 0.583 & -0.198 & 0.428 & $\mathbf{0 . 7 2 0}$ \\
\hline
\end{tabular}

\subsection{Structural Model}

By using Smart PLS v3 and bootstrapping technique with 5000 iterations structural model and hypotheses were tested. In addition, for the explanation power the standardized $R^{2}$ and for assessing the model fit standardised root mean square residual (SRMR) were computed. According to the structural model, SRMR value was observed 0.073 which is under the recommended value of 0.08 , so it can be inferred that model has an acceptable. Standardized $R^{2}$ refers to the explanatory level of independent variable on dependent variable. The independent variable (job demand and job resources) explain $21 \%$ of the employees' safety behaviors. However, job demand and job resources explains $76 \%$ of the employees' job related strain levels. Figure 2 shows the results of the structural model analysis. 
Figure 2: Structural Model

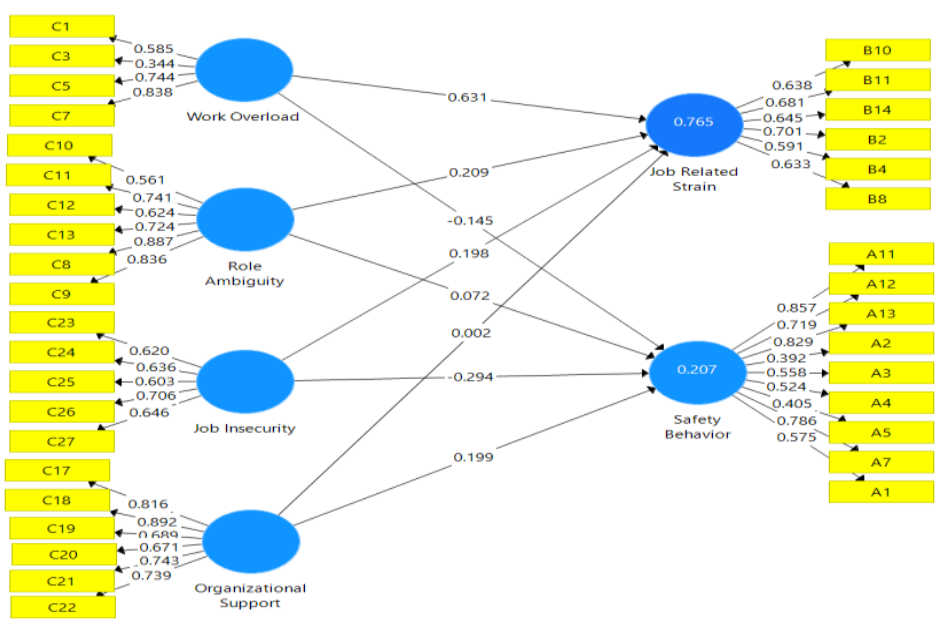

Table 3: Direct Effects of Structural Model and Path Coefficients

\begin{tabular}{|c|c|c|c|c|}
\hline Hypotheses & $\beta$ & T Values & P Values & Results \\
\hline $\mathrm{H}_{5}$ : Work overload -> Safety Behavior & -0.117 & 1.576 & 0.115 & Not Supported \\
\hline $\mathrm{H}_{1}$ : Work overload -> Job Related Strain & 0.491 & 10.579 & 0.000 & Supported \\
\hline $\mathrm{H}_{6}$ : Role Ambiguity -> Safety Behavior & 0.005 & 0.048 & 0.961 & Not Supported \\
\hline $\mathrm{H}_{2}$ : Role Ambiguity > Job Related Strain & 0.268 & 3.867 & 0.000 & Supported \\
\hline $\mathrm{H}_{7}$ : Job Insecurity-> Safety Behavior & -0.218 & 2.394 & 0.017 & Supported \\
\hline $\mathrm{H}_{3}$ : Job Insecurity -> Job Related Strain & 0.157 & 2.553 & 0.011 & Supported \\
\hline $\begin{array}{l}\mathrm{H}_{8} \text { : Organizational Support -> Safety } \\
\text { Behavior }\end{array}$ & 0.204 & 2.104 & 0.035 & Supported \\
\hline $\begin{array}{l}\mathrm{H}_{4} \text { : Organizational Support -> Job Related } \\
\text { Strain }\end{array}$ & -0.003 & 0.044 & 0.965 & Not Supported \\
\hline
\end{tabular}

According to table 3, it is possible to express that the path parameter and significance levels show that while job demands one of the dimension such as work overload $(\beta=0.491$; $t$-value $=10.579)$ has a positive and significant effect on job related strain levels of blue collar employees, it has no significant effect $\left(\beta=-0.117\right.$; $\mathrm{t}$-value=1.576) on safety behavior, so $\mathrm{H}_{1}$ supported but $\mathrm{H}_{5}$ was not supported. However, other dimensions role ambiguity $(\beta=0.268$; $t$-value=3.867) and job insecurity $(\beta=0.157 ; t-v a l u e=5.553)$ have a positive and significant effect on blue collar employees job related strain levels; $\mathrm{H}_{2}$ and $\mathrm{H}_{3}$ hypotheses were supported. In addition job insecurity also has a significant and negative effect $(\beta=-0.218$; $t$-value $=2.394)$ on safety behavior levels of blue collar employees, thus $\mathrm{H}_{7}$ hypothesis was supported. On the other hand, while one of the job resources dimension labelled as organizational support ( $\beta=0.204$; $t$-value $=2.104$ ) has a positive and significant effect on employees safety behaviors levels, so $\mathrm{H}_{8}$ was supported, but it has no significant effect on job related strain levels so $\mathrm{H}_{4}$ was not supported.

\section{CONCLUSION}

Job demands and job resources model include the negative and positive aspects of the jobs in an organizational context. While job demands composed of unfavourable components such as work overload, role ambiguity, role conflict and job insecurity; job resources arised from positive characteristics of the job like organizational support, feedback, autonomy and etc. However, job demands and job resources represent overarching model which lead to positive and negative outcomes simultaneously. In other words, it is suggested that while job demands cause to burnout, depression, strain, health problems and negative attitudes such as deviance, aggression and unsafety; job resources provide engagement and commitment, lead to increasing job performance and enable employees to exihibit more positive attiudes such as in a helpful and safety manner. Accordingly, it is possible to express that due to the high job demands in working area, employees may prone to emotional exhaustion and job related strain. On the other hand, in case of the high job resources, it is expected that employees have power to take precautions and behave more safely. Therefore, as scope of the consequences of job demands and job resources model; job strain and safety behavior were examined in this study.

As a result of the research findings, it has been found that all dimensions of job demands such as work overload, role ambiguity and job insecurity have a positive and significant effect on employees job related strain levels. This results reveal that unfavourable job characteristics may lead employees' well-being levels affected negatively and cause to some health problems. Because high job 
demands to make complicated blue collar workers to handle work and social life problems. In addition, just one of the dimension of job demands which labelled as job insecurity has a negative and significant effect on blue collar workers safety behaviors. Due to the perception of probability of loosing job in the further, it is expected that emloyees may have more careless and messy which tend to have an accident, injury or unsafe manner. Thus, it is possible to express that job insecurity perception considered as one of the main source of high job demands. On the other hand, from the job resources dimension, organizational support has a positive and significant effect on blue collar workers safety behavior levels. Therefore, it can be inferred that while employees have believed that their organization's trusted and valued them, they may exhibit positive attitudes. That is to say, in case of the organization give an opportunity to developing, learning and career advancement of their employees, they have a tendency to make an extra effort for the benefit of organization.

In conclusion, job demands and job resources which characterizes aspects of the job lead to some individual and organizational consequences. There are considerable studies in the literature that emphasizes the consequences of job demands and job resources, but there is no study focus on the relationships among job demands and job resources model, job related strain and safety behaviors on blue collar workers. Based on the job demands take an important part of blue collar working life, its detrimental effect such as job related strain and safety behaviors were analyzed in this study. According to the research results, it is supposed to decreasing of job demands like work overload, role ambiguity and job insecurity in order to provide safety behavior. Because, it is expected that job demands lead to fatigue and carelessness which cause to unsafe attitudes. Besides, by reducing of job demands, it is possible to increase employees' well-being levels which provide motivation and favourable behaviors in the long term. On the other hand, organizations need to put emphasis on to give some oppurtunities to their employees that cause them to be motivated and have a tendency to develop themselves. In future, it is recommended that the research model can be tested different occupations such as nurses, sales representatives, construction workers and etc. which have high job demands and low job resources. Furthermore, from an organizational perspective; by taking job characteristics and quality of work life its adverse effect can be investigated on safety behaviors and job related strain levels of blue collar workers.

\section{REFERENCES}

Adil, M. S. \& Baig, M. (2018). Impact of job demands-resources model on burnout and employee's well-being: Evidence from the pharmaceutical organisations of Karachi, IIMB Management Review, 30, 119-133.

Anderson, J.C. \& Gerbing D.W. (1988). Structural equation modelling in practice: A review and recommended two-step approach. Psychological Bulletin, 3 (3), 411-423.

Aslan, S.H., Alparslan, N.Z., Aslan, R.O., Kesepara, C. \& Ünal, M. (1998). İşe Bağlı Gerginlik Ölçeğinin Sağlık Alanında Çalışanlarda Geçerlik ve Güvenirliği. Düşünen Adam, 11 (2): 4-8.

Bakker, A.B. \& Demerouti, E. (2007). The Job Demands-Resources Model: State of the art. Journal of Managerial Psychology, Vol. 22 No. 3, 309-328.

Bronkhorst, B. (2015). Behaving safely under pressure: The effects of job demands, resources, and safety climate on employee physical and psychosocial safety behavior, Journal of Safety Research, 55, 63-72.

Brough, P., Timms, C., \& Siu, O. (2013). Validation of the Job Demands Resources model in cross national samples: Cross-sectional and longitudinal predictions of psychological strain and work engagement, Human Relations, 66(10), 1311-1335.

Chavarria, D. E. (2016). Analyzing the Relationship between Job Demands, Job Resources, and Personal Resources on Employee Engagement and Exhaustion of Juvenile Probation/Parole Officers, UNLV Thesis, University of Nevada, Las Vegas.

DeArmond, S. \& Chen, P.Y. (2009). Occupational safety: The role of workplace sleepiness, Accident Analysis and Prevention, 41, 978.

Demerouti, E. \& Bakker, A. B. (2011). The Job Demands-Resources model: Challenges for future research, SA Journal of Industrial Psychology, 37(2), 1-9.

Demerouti, E., Bakker, A. B., Nachreiner, F. \& Schaufeli, W. B. (2001). The Job Demands-Resources model of burnout, Journal of Applied Psychology, 86(3), 499-512.

Fernández-Mu niz, B., Montes-Peón, J.M. \& Vázquez-Ordás, C.J. (2012). Safety climate in OHSAS 18001-certified organisations: Antecedents and consequences of safety behaviour, Accident Analysis and Prevention, 45, 746.

Fernet, C., Austin, S. \& Vallerand, R. J. (2012). The effects of work motivation on employee exhaustion and commitment: An extension of the JD-R model, Work \& Stress, 26(3), 213-229.

Fornell, C., \& Larcker, D. F. (1981). Evaluating structural equation models with unobservable variables and measurement error. Journal of Marketing Research, 18(1), 39-50.

Hansez, I. \& Chmiel, N. (2010). Safety Behavior: Job Demands, Job Resources, and Perceived Management Commitment to Safety, Journal of Occupational Health Psychology, 15(3), 267-278. 
Hair, J. F., Black, W. C., Babin, B. J., Anderson, R. E., \& Tatham, R. L. (2006). Multivariate Data Analysis (6th ed.). Upper Saddle River, NJ: Prentice-Hall.

Ju, D., Qin, X., Xu, M. \& DiRenzo, M.S. (2016). Boundary conditions of the emotional exhaustion-unsafe behavior link: The dark side of group norms and personal control, Asia Pac J Management, Vol. 33. No. 113, 114.

Kanten, P. (2018). “Güvenli Davranışlar”. İş Sağlığı ve Güvenliği Yönetimi içinde, (Ed: S.Kanten): Nobel Yayıncılık: Ankara.

Khan, N.H.A.L., Ghazali, Z. \& Isha, A.S.N., (2014). The Role of Leadership and Leaders' Behavioral Characteristics on Employees' Safety Behavior in Plant Turnaround Maintenance of PETRONAS Petrochemical Companies in Malaysia, Global Business and Management Research: An International Journal, Vol. 6, No. 3, 258.

Li, F., Jiang, L., Yao, X. \& Li, Y. (2013). Job demands, job resources and safety outcomes: The roles of emotional exhaustion and safety compliance, Accident Analysis and Prevention, 51, 243-25.

Lopes, C. S., Araya, R., Werneck, G. L., Chor, D. \& Faerstein, E. (2009). Job strain and other work conditions: relationships with psychological distress among civil servants in Rio de Janeiro, Brazil, Soc Psychiat Epidemiol, 1-10.

Nahrgang, J. D., Morgeson, F. P. \& Hofmann, D. A. (2010). Safety at Work: A Meta-Analytic Investigation of the Link between Job Demands, Job Resources, Burnout, Engagement, and Safety Outcomes, Journal of Applied Psychology, 1-24.

Schaufeli, W. B. (2017). Applying the Job Demands-Resources model: A 'how to' guide to measuring and tackling work engagement and burnout, Organizational Dynamics, 46, 120-132.

Seo, D. (2005). An explicative model of unsafe work behavior, Safety Science, 43, 199.

Strydom, M. (2005). A Psychometric Evaluation of the Job Demands and Resources Scale in South Africa. The degree Magister Artium in Industrial Psychology at the North-West University.

Roy, S.J., Lassar, W.M. \& Shekhar, V. (2016) Convenience and satisfaction: mediation of fairness and quality, The Service Industries Journal, 36:5-6, 239-260.

Turcotte, M. \& Schellenberg, G. (2005). Job strain and retirement, Perspectives on Labour and Income, 17(3), 13-17.

Turner, N., Hershcovis, M. S., Chmiel, N. \& Walls, M. (2010). Life on the Line: Job Demands, Perceived Co-Worker Support for Safety, and Hazardous Work Events, Journal of Occupational Health Psychology, 15(4), 482-493.

Wingerden, J., Bakker, A. B. \& Derks, D. (2016). A test of a job demands-resources intervention, Journal of Managerial Psychology, 31(3), 686-701. D

Wolter, C., Maria, A. S., Wörfel, F., Gusy, B., Lesener, T., Kleiber, D. \& Renneberg, B. (2019). Job Demands, Job Resources, and Wellbeing in Police Officers-a Resource-Oriented Approach, Journal of Police and Criminal Psychology, 34, 45-54. 